Pensares em Revista, ISSN 2517-2215

\title{
ALFABETIZAÇÃO E ENSINO DA LINGUAGEM NA ESCOLA NO CONTEXTO DA CULTURA ESCRITA
}

\author{
Cecilia M. A. GOULART \\ (Universidade Federal Fluminense) \\ goulartcecilia@yahoo.com.br
}

\begin{abstract}
Resumo: $O$ artigo focaliza aspectos do trabalho com a linguagem na escola, estabelecendo relações entre as expressões cultura escrita, letramento e ensino-aprendizagem da linguagem, desde o período da alfabetização. A discussão é realizada no sentido de problematizar a função social e política da instituição escola e o importante papel da linguagem em nossas vidas. Fundamenta-se nos estudos da linguagem de Bakhtin, tomando como ponto de partida o enunciado como objeto de significação da cultura, social e histórico, um tecido organizado e estruturado e a dificuldade histórica que a escola apresenta de realizar mudanças no ensino da língua. Muito mais do que compreender como funciona a modalidade escrita da linguagem verbal, saber ler e escrever socialmente é ter acesso ao mundo da escrita na escola e na vida.
\end{abstract}

Palavras-chave: Cultura escrita. Letramento. Ensino-aprendizagem da linguagem.

\section{ALFABETIZAÇÃO E ENSINO DA LINGUAGEM NA ESCOLA NO CONTEXTO DA CULTURA ESCRITA}

\begin{abstract}
This study focuses on some aspects of the pedagogical work with language at school, establishing some relations among the following constructs: written culture, literacy, and language teaching-learning from the very early stages of literacy acquisition. Therefore, the discussion held here aims at problematizing the political and social function of the school as an institution, and the important role that language plays in the lives of human beings. The research has Bakhtin's language studies as its basis and the utterance - seen as the social and historical meaning making object of culture - as its starting point. Here, the utterance can be seen as some organized and structured fabric. In what concerns this study, it is relevant to note the historical difficulty that school has faced regarding changes in language teaching. Hence, to the learner, more than mastering the written aspect of the language, being able to read and write means having access to the writing world at school and in life.
\end{abstract}

Keywords: Cultura escrita. Letramento. Ensino-aprendizagem da linguagem. 


\section{Introdução ao tema e problema}

A complexidade das questões sociais nos obriga a pensar também complexamente sobre aspectos da realidade da educação escolar brasileira. Sob esta afirmação, o artigo tem como objetivo focalizar, ainda que de modo breve, aspectos do trabalho com a linguagem na escola, tema que transpassa esta realidade de muitas maneiras. Estabeleço relações entre as expressões cultura escrita, letramento e ensino-aprendizagem da linguagem, desde o período da alfabetização, discutindo-as no sentido de problematizar a função social e política da instituição escola e o importante papel da linguagem em nossas vidas.

Não é demais lembrar, para começar a conversa, que ainda temos índices altos de analfabetismo absoluto na população brasileira, além de preocupantes dados sobre alfabetismo funcional, informando-nos sobre jovens e adultos que passaram anos na escola, sendo muitas vezes considerados alfabetizados, mas que não dão conta de atividades sociais de leitura e de escrita características da vida de cidadãos. Estes são, portanto, desafios políticos, sociais, culturais e educacionais a que não podemos nos furtar de considerar.

O premiado documentário Pro dia nascer feliz', de João Jardim², realizado em co-produção com Flávio $R$. Tambellini, apresenta elementos importantes para refletirmos sobre as realidades brasileiras, já que jovens têm a palavra e são ouvidos no filme. Como informa a sinopse do filme, definido pelo próprio diretor como "um diário de observação da vida do adolescente no Brasil em seis escolas", Pro Dia Nascer Feliz capta:

o dia-a-dia e adentra a subjetividade de alunos e alunas e alguns professores nas seguintes cidades: Manari, Pernambuco, uma das cidades mais pobres do Brasil, a violenta Duque de Caxias no Rio de Janeiro e no Estado de São Paulo, temos o rico bairro de Alto de Pinheiros na capital e a precária Itaquaquecetuba a $50 \mathrm{~km}$ do centro da cidade.

\footnotetext{
1 Roteiro, direção e edição: João Jardim. Produção: Flávio R. Tambellini e João Jardim. Produtoras: Tambellini Filmes e Fogo Azul Filmes. Produtora associada: Casa Redonda. Distribuição: Copacabana Filmes. Duração: 88 minutos.

${ }^{2}$ Cineasta, autor de Janela da Alma/2002, entre outros.
} 
Tomando conhecimento das cidades e dos espaços onde moram os jovens entrevistados no filme, já nos é possível imaginar a diversidade apresentada. Disse o diretor do filme: "Eu parti para a ideia de fazer um corte longitudinal no país e mostrar diferentes Brasis". Não entro em detalhes sobre 0 desenvolvimento do instigante documentário. Trago-o aqui para que, por meio de algumas falas de jovens, ilustrar como aspectos do cenário social são compreendidos por adolescentes de diferentes regiões do país. Destaco, assim, também na escola, a importância de ouvi-los para conhecê-los e conceber metodologias de trabalho pedagógico. Vamos a algumas falas de jovens selecionados para o filme.

\footnotetext{
"É muito romântico falar 'a gente é igual.' Eu tenho o que comer e eles não têm, entendeu? Na essência a gente é igual, mas a gente tá submetido a dois mundos muito diferentes".

(Mariana, 16 anos, Alto Pinheiros, São Paulo, capital)

"Aqui na maioria das vezes não tem nem chance de sonhar". (Valéria, 16 anos, Manari, sertão de Pernambuco)

"Antes eu chegava da escola, deitava na cama e ficava o dia inteiro dormindo. Comia até deitada na cama, porque pra mim seria a solução dos meus problemas, morrer. Seria mais fácil o caminho."

(Keila, 16 anos, Itaquaquecetuba, Grande São Paulo)

"Eu acho assim, quando um professor falta, eu falo:
}

'Opa, graças a Deus, agora eu posso zoar bastante.'”

(aluna da rede pública, subúrbio do Rio de Janeiro)

"Pôxa, os próprios caras grandes, lá, roubam da sociedade.

Aí nós, que somos, vamos dizer assim..., a sociedade que é minoria, nós não vamos roubar por causa de quê? (...)

A criminalidade existe por causa deles mesmo, pô.

Eles plantam e estão colhendo o que plantaram".

(menor infrator)

"Eu não queria ir pra escola, parei de sair com as minhas amigas, não conseguia estudar, chegava na hora da prova me dava branco e eu não conseguia lembrar das coisas, daí teve que ir cuidando de uma coisa, de outra..."

(Thais, 15 anos, Alto Pinheiros, São Paulo)

Eu deveria ter uma péssima impressão da vida

se não fosse a paixão que tenho pela arte de viver.

(últimos versos de um poema de Valéria, 16 anos, Manari, sertão de Pernambuco)

Pensares em Revista, São Gonçalo-RJ, n. 6, pág. 9-22, jan. / jun. 2015 
Os enunciados dos jovens são plenos de percepções, sentimentos, valores e conhecimentos. Mostram contradições percebidas por eles mesmos e impressões sobre suas vidas e acontecimentos sociais e escolares. A arte renova nosso olhar para a realidade e assim também aprendemos. Por isso ilustramos o artigo com o filme de João Jardim. De acordo com Bakhtin (1998, p. 30), a obra de arte é viva e significante do ponto de vista cognitivo, social, político, econômico e religioso num mundo também vivo e significante. A atividade estética enriquece e completa a realidade da natureza e da humanidade social preexistente ao conhecimento e ao ato ético, criando a unidade concreta desses dois mundos.

Refletindo na direção da unidade concreta do mundo da vida e da arte, e considerando as falas dos jovens no filme, chama atenção a histórica dificuldade que alunos têm na escola de compreender e elaborar o discurso verbal, oral e escrito, especialmente em enunciados escritos mais formais, de áreas do conhecimento que se distanciam da linguagem social do cotidiano. Há falas de professores sinalizando a falta de entendimento dos alunos, bem como falas de alunos dando depoimento sobre a impossibilidade muitas vezes de compreender o que é ensinado e mesmo o que se espera deles. A impossibilidade de traduzir em enunciados o que lhes é ensinado, o que se tem a expectativa de que deveriam ter aprendido. O que acontece? Por que pessoas que conseguem fazer leituras do mundo, dar soluções a problemas e criar hipóteses sobre situações e experiências da vida apresentam este tipo de dificuldade? Por que muitas vezes o silêncio nas salas de aula é a saída? Ou por que a incompreensão do que se passa na escola outras vezes se explicita reativamente por gestos e palavras violentas?

Com certeza este é um tema altamente desafiador e complexo que pode ser estudado por muitos vieses. Tentamos cercá-lo do ponto de vista dos estudos da linguagem com base em Bakhtin. Tomamos como ponto de partida o enunciado que, de acordo com este autor, é o objeto dos estudos da linguagem: objeto de significação e da cultura, social e histórico, um tecido organizado e estruturado. Deve ser analisado nas relações internas e externas: sua organização, a interação verbal, o contexto - as condições de produção. Nele habitam muitas vozes sociais, que se completam, polemizam, respondem 
umas às outras. Mesmo o silêncio é entendido discursivamente como o silêncio de palavras caladas, não é um silêncio mudo, de quem não tem o que dizer, mas um silêncio de enunciados impedidos (por razões variadas) de serem externados.

Os enunciados citados acima, integrantes do documentário Pro dia nascer feliz, foram elaborados no contexto das histórias de vida de seus jovens falantes, de seus interlocutores, dos locais onde foram criados e cresceram, entre muitos outros fatores. Organizam-se interna e externamente como frutos do processo de interação com muitas outras pessoas, na interdialogização de muitos outros enunciados, humanizando e marcando os sujeitos de muitas maneiras. O mesmo acontece com as falas, os enunciados, de nossas crianças e jovens na escola. Mas como?

\section{1 - A escola, suas funções e ações}

A entrada de crianças na escola apresenta a tomada de conhecimento de novos discursos, novas referências do mundo, de naturezas diferentes daquelas do espaço privado da casa, da família e de grupos sociais mais próximos. Estes novos discursos são novas formas de olhar a realidade, de ler o mundo, com que em muitos casos as crianças e mesmo os jovens nunca suspeitaram. Modos diferentes ligados a valores diferentes que podem causar estranheza àqueles que têm suas vidas afastadas dos valores dominantes da sociedade. Este é o caso de determinados grupos populares, grupos rurais e outros.

A aprendizagem da escrita está diretamente ligada à tomada de conhecimento de novas realidades, associadas a novas áreas de conhecimento e a novos modos de organizar institucionalmente a sociedade. Ensinar-aprender a ler e a escrever se inscreve no movimento de participação na cultura letrada. Muito mais do que compreender como funciona a modalidade escrita da linguagem verbal, saber ler e escrever socialmente é ter acesso ao mundo da escrita na escola e na vida.

E como conceber que a aprendizagem da escrita e o acesso ao mundo da escrita se deem de forma conjugada, de modo pleno, transformando a 
condição daquele que se alfabetiza? A aprendizagem do princípio alfabético da língua escrita e a aprendizagem dos modos como a escrita se estabelece na sociedade e a organiza não devem ser apartados. Quando aprendemos a ler e a escrever devemos aprender juntamente o que a escrita faz conosco, já que este conhecimento nos inscreve de modo específico no espaço cultural, e também o que podemos fazer com a escrita socialmente, ou seja, que mudanças incorporamos ao nosso modo de vida para participar mais integralmente dos caminhos da sociedade, para compreender, entre outras relações, como se estabelecem as relações de poder.

O processo de adentrar o conhecimento da escrita como sistema de representação propriamente e como linguagem com seus usos e funções sociais tem provocado nossa atenção para o trabalho que inevitavelmente é realizado com gêneros do discurso na escola. Esta categoria é inerentemente ligada à categoria dos enunciados bakhtinianos. Segundo Bakhtin (1992, p. 301-302),

...gêneros do discurso nos são dados quase como nos é dada a língua materna, que dominamos com facilidade antes mesmo que lhe estudemos a gramática. ... Aprender a falar é aprender a estruturar enunciados. ... Os gêneros do discurso organizam nossa fala da mesma maneira que a organizam as formas gramaticais. (1992, p. 301-302)

Não nos é possível falar e escrever sem que se produzam gêneros; tratase de uma categoria com muitas possibilidades metodológicas do ponto de vista teórico e prático, e por isso mesmo de abordagem muito difícil quando temos como horizonte o trabalho pedagógico.

Bakhtin entende que a sucessiva integração e aprofundamento dos sujeitos na vida social os tornam mais livres e criativos para reformular gêneros padronizados (GOULART, 2013, p. 82). Decorre daí que, segundo o autor, o maior domínio e emprego de gêneros podem levar os sujeitos para além da descoberta da potencialidade criadora, realizando de modo mais acabado o livre projeto de discurso (Bakhtin, 2003, p. 285), o que entendemos como a constituição do sujeito mais consciente de suas atitudes e atividades, organizando a vida social com autoria, com assinatura. 
Há um aspecto a salientar, já que consideramos a oralidade como grande mediador de conhecimentos de várias naturezas, inclusive do conhecimento da própria escrita, no processo de aprender na escola. O conhecimento de gêneros utilizados para falar não pode ser simplesmente transferido para a escrita. Há todo um movimento de reorganização discursiva na mudança da modalidade oral para a modalidade escrita, ressalvando-se traços e sentidos comuns.

Como destacamos em 2009 (GOULART, 2009), Bakhtin sinaliza que toda a atividade mental, tanto a que é exteriorizada quanto a interior, se constitui em signos ideológicos e pode ser expressa, não havendo uma ruptura qualitativa de uma esfera de realidade a outra (BAKHTIN, 1988, p. 51-52). De modo complementar e singular, o autor afirma: "Não é a atividade mental que organiza a expressão, mas, ao contrário, é a expressão que organiza a atividade mental, que a modela e determina sua orientação" (1988, p. 112). Ou seja, o centro organizador e formador da expressão se situa no movimento do exterior para o interior (do social para a individualidade dos sujeitos). Do ponto de vista deste artigo e da proposta de trabalho escolar que delineia, esta afirmação sugere de modo forte um papel importante na escola para as conversas, leituras e interações sociais de diferentes tipos.

\section{2 - Aspectos do processo de ensino-aprendizagem da linguagem na escola}

Desde a década de 1980, na esteira do processo de abertura política no Brasil, muitas propostas curriculares de Alfabetização e de Língua Portuguesa vêm sendo concebidas e discutidas. A crítica ao ensino da linguagem (também no período de alfabetização) nos moldes de estudos taxionômicos da língua e de estudos estruturalistas era e é muito forte. A grande discussão, animada com a mudança política conquistada, levou a muitos e importantes estudos e a propostas de alteração dos princípios que pautaram propostas anteriores à década de 1980, inserindo neste novo contexto os sujeitos que aprendem e seus processos de ensino-aprendizagem. Influências destes novos parâmetros se manifestam nos PCN - Parâmetros Curriculares Nacionais (BRASIL, 1998) 
e em propostas de secretarias estaduais e municipais, de várias formas, embora problemáticas e contraditórias às vezes. Este tópico, entretanto, não faz parte do cardápio do presente artigo.

No trabalho escolar, a linguagem quase sempre foi considerada um elemento sem peso, equiparada ao estudo das unidades da língua; por este aspecto metodológico podemos associá-la ao modelo autônomo de letramento de Street (1984; 2003). De acordo com o autor, neste modelo, prioriza-se a análise da língua, subordinando seus falantes e sua existência social ao estudo de características estruturais do sistema linguístico. Os sujeitos e suas vidas desaparecem, suas histórias não têm importância, como se todos aprendessem de um mesmo modo, seguindo um mesmo caminho. O foco dessas propostas é o objeto língua e o modo como esta se organiza.

A partir do período de alfabetização, nos anos iniciais do Ensino Fundamental, prevalece o ensino da leitura e da escrita de letras relacionadas a sons, sílabas, palavras, frases e orações - destaque, portanto, para os aspectos formais, descolados de situações enunciativas, para se exigir nas avaliações que os alunos interpretem e elaborem textos de forma contextualizada socialmente (cf. FIORIN, 2005, p. 9). A escrita é apresentada como um código, como algo a aprender instrumentalmente, obscurecendo-se seu protagonismo na sociedade, seus valores e o fato de que este bem cultural é um grande segregador de pessoas: quem o possui está dentro do cinturão de poder e quem não o possui, está fora, já que o cinturão é preponderantemente tecido pelos produtos e valores que compõem a chamada cultura escrita.

É neste momento que fazemos ressalvas ao conceito de letramento, que muitas vezes é colocado em disputa com a expressão cultura escrita. De um modo geral, quando se discute o binômio alfabetização-letramento (SOARES, 1998; e outros), associa-se o conceito de letramento a práticas sociais que se organizam em torno da linguagem escrita. A ressalva que fazemos diz respeito à redução da cultura escrita na perspectiva do conceito de letramento. Há o perigo de empobrecer os sentidos políticos e culturais múltiplos que a expressão cultura escrita envolve, ligando-a somente a práticas sociais de escrita e leitura. Nestes sentidos estão gestos, objetos, procedimentos, atividades e eventos, abrindo em leque a sua complexidade. 
Outro aspecto entranhado na discussão que apresentamos é a construção da autoria. Os sujeitos são pessoas socialmente constituídas, entretanto possuem instâncias de individualidade que também se organizam na relação exterioridade-interioridade-exterioridade. Nesse movimento, acontece a compreensão, um processo discursivo sempre renovado por uma integração reiterada no contexto interior, e, de modo correlato, a expressão, que renova a síntese dialética entre a vida interior e a vida exterior, revelando-se como o produto da interação viva das forças sociais. Por sua natureza dialógica, originado de palavras alheias, o enunciado da compreensão/expressão apresenta-se como uma arena onde lutam valores sociais de orientação contraditória (GOULART, 2009, p. 9).

$\mathrm{Na}$ direção do trabalho com a linguagem na escola, Possenti (2001) analisa a compatibilização dos conceitos de enunciação, autoria e estilo. De acordo com o autor, estilo pode ser entendido "como um certo modo de organizar uma sequência (de qualquer extensão), focando-se como fundamental a relação entre essa organização e um determinado efeito de sentido (...)". Possenti interliga a noção de estilo ao modo como a construção composicional do texto produz sentido, afirmando que, em relação ao estilo, a escolha é uma categoria constitutiva. Segundo ele, a escolha de palavras e das próprias construções não decorre simplesmente da avaliação das alternativas por parte de um sujeito-autor onisciente e todo-poderoso. O sujeito não toma decisões na produção de textos livre de amarras institucionais.

$O$ estudo do autor nos encaminha para importantes reflexões sobre 0 trabalho alfabetizador e sobre o ensino de língua portuguesa na escola. O que é alfabetizar? O que significa ensinar língua portuguesa? Que tipos de atividades contribuem para que as crianças e os jovens usufruam cada vez mais da língua materna na sociedade?

E Possenti chama a atenção de que quando falamos ou escrevemos de determinado modo, escolhemos não dizer de outro. Afirma que a escolha seja uma necessidade estrutural, condicionada por determinados fatores, sendo um dos efeitos da multiplicidade de recursos de expressão disponíveis. Estes recursos competem entre si o tempo todo. Para o autor, a escolha na produção 
de enunciados não é um ato de liberdade, mas o efeito de uma inscrição, genérica, social, discursiva (POSSENTI, 2001, p. 17).

\section{3 - Questões que permanecem no horizonte para serem estudadas, enfrentadas}

Muitas questões são desencadeadas com base nas relações tecidas e nas questões apresentadas. Como aspectos como estes, intrinsecamente ligados à construção do estilo e da autoria dos sujeitos são trabalhados na escola? Como podem ser trabalhados? Como sujeitos dão sentido ao que aprendem (GOULART, 2005; 2007; 2009; 2010; 2011; 2013)? De que modo expressam por escrito o que estão em processo de aprender? Na linguagem, pelo seu caráter de regulação e normatização, constituem-se modos de apreensão de sentidos e também, pelo seu caráter de indeterminação, modos de transformação de sentidos. Estas duas dimensões - a norma linguística e a parcela de indeterminação dos sentidos - devem estar presentes no trabalho de qualquer sala de aula.

Os períodos abaixo são apresentados por Garcia (1967 [1978]) em seu livro Comunicação em prosa moderna como um exercício a ser realizado com alunos para ampliar sua competência discursiva. Certamente não é para ser feito mecanicamente. A demanda principal é observar o que muda de um período para outro quando eles são transformados. Como os sentidos se alteram? Onde a ênfase se coloca? Quem fala em cada situação? Como os diferentes períodos produzem sentido, considerando a escolha das diferentes construções composicionais?

1- A Quinta da Boa Vista é um belo parque. Esse parque fica no bairro de São Cristóvão. Foi em São Cristóvão que eu nasci. Ainda moro hoje aí.

2- Situada em São Cristóvão está a Quinta da Boa Vista, que é um belo parque; foi em São Cristóvão que eu nasci e é aí que ainda resido.

3- Nasci e ainda resido no bairro de São Cristóvão, onde está situada a Quinta da Boa Vista, que é um belo parque. 
4- A Quinta da Boa Vista, que é um belo parque, está situada em São Cristóvão, bairro onde nasci e ainda resido.

5- Nasci e ainda resido em São Cristóvão, onde está situada a Quinta da Boa Vista, que é um belo parque.

(Garcia, 1967[1978], p. 127).

Não seria esta atividade um exemplo de exercício para ensinar a língua e sua gramática, a serviço do aprofundamento dos conhecimentos dos alunos? $\mathrm{O}$ universo de sentidos é que comanda a atividade.

A escola pode ter um papel importante no enriquecimento linguístico cada vez maior dos alunos, de forma que eles participem com legitimidade dos movimentos da cultura letrada. A afirmação seguinte de Bakhtin é uma relevante referência neste sentido: "nossa transformação ideológica é justamente um conflito tenso no nosso interior pela supremacia dos diferentes pontos de vista verbais e ideológicos, aproximações, tendências, avaliações" (BAKHTIN, 1998, p.146, grifo nosso). Para que exista o conflito tenso é preciso haver multiplicidade de conversas, de textos, de autores.

Iniciamos o artigo lembrando da produção importante de estudos e de propostas político-pedagógicas de alfabetização e de ensino de linguagem na década de 1980. Sabemos, entretanto, que ainda hoje muitas salas de aula são marcadas pelas características do programa estruturalista, conforme destaca Abaurre (1994), considerando o treino de estruturas da língua materna como garantia de aprendizagem, desde as séries iniciais, na fala e na escrita. Salomão, em 2009, por sua vez, continua criticando, no ensino, a marca do estruturalismo no estudo de organizações fônicas, morfológicas e, mais limitadamente, sintáticas. Critica 0 trabalho realizado com 0 foco no significante, que é segmentado até obter elementos mínimos (fones, fonemas, traços fônicos, morfemas, lexemas, classes sintáticas), em termos de suas propriedades combinatórias e distribucionais. Salomão destaca que o custo dessa abordagem tem sido a exclusão do sujeito como usuário da linguagem. 
Pelo caráter formativo da escola, e considerando a importância do desafio à criação e à aprendizagem crítica, as práticas pedagógicas com a linguagem devem abrir janelas para argumentos e pensamentos de todos os tipos. Crianças e jovens pensam, sentem, imaginam e propõem, se tiverem espaço para tais ações, como destacamos no filme Pro dia nascer feliz. A aprendizagem da leitura e da escrita com base em textos gerados nos muitos meandros da cultura escrita, e para esta mesma cultura, se fortalece com a possibilidade de os alunos mergulharem nos sentidos dos textos que falam, ouvem e leem, para inventarem novos sentidos para os textos que escrevem. A gramática da língua desse modo pode ser entendida como um sistema aberto a uma multiplicidade de escolhas dos sujeitos, no plural. Escolhas contextualizadas, discutidas, criticadas, assumidas e entendidas no contexto da vida social, da cultura letrada, influenciando e condicionando a formação de cidadãos críticos.

\section{Referências}

ABAURRE, Maria Bernadete Marques. A Alfabetização na Perspectiva da Lingüística: Contribuições Teórico-Metodológicas. Cadernos ANPEd, 6, out.1994.

BAKHTIN, Mikhail. Estética da criação verbal. Tradução de Maria Ermantina Galvão G. Pereira. São Paulo: Martins Fontes, 1992.

BAKHTIN, Mikhail (V. N. Voloshinov). Marxismo e filosofia da linguagem. Tradução de Michel Lahud e Yara Frateschi Vieira. 4⿳亠丷厂 edição. São Paulo: Hucitec, 1988.

BAKHTIN, Mikhail. Questões de literatura e de estética: a teoria do romance. Trad. Aurora Fornoni Bernadini et alii. São Paulo: HUCITEC/ UNESP, 1998.

BAKHTIN, Mikhail. Estética da criação verbal. Tradução do russo de Paulo Bezerra. São Paulo: Martins Fontes, 2003.

BRASIL. Ministério da Educação e do Desporto. Parâmetros Curriculares Nacionais. Parâmetros curriculares nacionais: Língua Portuguesa (1 ${ }^{a}$ a $4^{a}$. série), 1998. 
FIORIN, José Luiz. Elementos de análise do discurso. São Paulo: Contexto, 2005 [1989].

GARCIA, Othon M. Comunicação em prosa moderna. 7aㅡ Ed., Rio de Janeiro: Fundação Getúlio Vargas, 1978 [1967].

GOULART, Cecilia M. A.. Política como ação responsiva - breve ensaio sobre educação e arte. In.: FREITAS, M. T. (Org.). Educação, arte e vida em Bakhtin. Belo Horizonte: Autêntica, 2013, p. 69-93.

Cultura escrita e escola: letrar alfabetizando. In: MARINHO, Marildes e CARVALHO, Gilcinei Teodoro (Org.). Cultura escrita e letramento. Belo Horizonte, Editora UFMG, 2010, p.438-456.

A. Alfabetização, discurso científico e argumentação. In: LEITÃO, S. \& DAMIANOVIC, M. C. Argumentação na escola: o conhecimento em construção. São Paulo: Pontes, 2011, p.129-151.

Sujeitos, espaços educativos e processos de ensinoaprendizagem: uma discussão a partir de Bakhtin. Revista TEIAS (online), v. 10, n.19,p. 2009. <http://www.periodicos.proped.pro.br/index.php?journal=revistateias>

Processos de letramento na infância: aspectos da complexidade de processos de ensino-aprendizagem da linguagem escrita. In: SCHOLZE, L. e RÖSING, T. M. K. (Org.). Teorias e práticas de letramento. Brasília: Instituto Nacional de Estudos e Pesquisas Educacionais Anísio Teixeira, 2007, p.61-82.

GOULART, Cecilia M. A. et alii. Processos de letramento na infância: modos de letrar e ser letrado na família e no espaço educativo formal. Relatório final de pesquisa. Universidade Federal Fluminense, Faculdade de Educação, CNPq, dezembro de 2005.

POSSENTI, Sírio. Enunciação, autoria e Estilo. In Revista Brasileira da FAEEBA, Salvador, no. 15, p. 15-21, jan./jun., 2001.

SALOMÃO, Maria Margarida Martins. A questão da construção do sentido e a revisão da agenda dos estudos da linguagem. In: Veredas: Revista de estudos linguísticos. Juiz de Fora, v. 3 - n. 1, 2009, p. 61-79.

SOARES, Magda B. Letramento - um tema em três gêneros. Belo Horizonte: Autêntica, 1998.

STREET, Brian V. Abordagens Alternativas ao Letramento e Desenvolvimento. Teleconferência UNESCO/Brasil sobre Letramento e Diversidade, outubro de 2003.

1984.

. Literacy in theory and Practice. Cambridge: University Press, 
Artigo recebido em: 15 de agosto de 2015

Artigo aprovado em: 01 de setembro de 2015

Sobre a autora:

Cecilia M. A. Goulart é Doutora em Linguística Aplicada (PUC, Rio, 1997). Realizou estágio de pós-doutorado na UNICAMP com a professora Ana Luiza Smolka (2014). É professora da Faculdade de Educação da UFF, atuando na graduação, pós-graduação e em atividades de extensão. Coordena o grupo de pesquisa Linguagem, cultura e práticas educativas, integrante do Diretório de Grupos de Pesquisa do Brasil/CNPq (desde 2001). É professora aposentada da rede de ensino do município do Rio de Janeiro. 